\title{
Perancangan Sistem Informasi Data Pelayanan Pengunjung Berbasis Web menggunakan Framework CodeIgniter dan UIkit (Studi Kasus: Perpustakaan dan Arsip Daerah Kota Salatiga)
}

\author{
Designing Web-based Visitor Service Data Information System using \\ CodeIgniter Framework and Uikit \\ (A Case Study: Regional Library and Archives of Salatiga City)
}

\author{
Adinda Setya Oktami ${ }^{1)}$, Evangs Mailoa ${ }^{2)}$ \\ 1,2)Program Studi Teknik Informatika, Universitas Kristen Satya Wacana, Salatiga
}

Diterima 6 Februari 2019 / Disetujui 27 Februari 2019

\begin{abstract}
Visitors are important for the library. To gain more visitors the library needs some services which available for visitors. Library and Archives of Salatiga (Persipda) has a lot of visitors and provides a variety of services. Visitor services data is a crucial thing that need to know about the level of quality of service. Quality of service can be known by the increasement or decreasement of the number of visitors' a service. Therefore, data information systems of visitor services required to manage data and find out the occurrence of increasement or decreasement in the number of visitor services. This information system has some features, such as highchart to display data of visitors form the database system.

Keywords: Library, Visitor, Servic Data.
\end{abstract}

\begin{abstract}
ABSTRAK
Pengunjung merupakan hal yang penting bagi Perpustakaan. Untuk mendapatkan pengunjung yang banyak diperlukan layanan yang tersedia bagi pengunjung. Perpustakaan dan Arsip Daerah Salatiga (Persipda) adalah salah satu perpustakaan di Salatiga yang memiliki banyak pengunjung dan menyediakan berbagai layanan pengunjung. Data pelayanan pengunjung merupakan hal yang penting untuk mengetahui tingkat kualitas pelayanan. Kualitas pelayanan dapat diketahui dengan terjadinya peningkatan atau penurunan jumlah pengguna suatu layanan. Oleh karena itu dibutuhkan sistem informasi data pelayanan pengunjung untuk mengelola data di pelayanan serta mengetahui terjadinya peningkatan atau penurunan jumlah pelayanan pengunjung. Sistem informasi ini dilengkapi fitur highchart untuk menampilkan data pengunjung dalam bentuk chart yang ada di database sistem.
\end{abstract}

Kata Kunci: Perpustakaan, Pengunjung, Data Pelayanan.

\section{PENDAHULUAN}

Perpustakaan merupakan sebuah tempat umum untuk mendapatkan berbagai informasi melalui media buku. Perpustakaan termasuk tempat yang dikunjungi banyak orang. Salah satu perpustakaan yang sering dikunjungi adalah Perpustakaan dan Arsip Daerah Kota Salatiga (Persipda). Persipda memiliki berbagai jenis pelayanan bagi

*Korespondensi Penulis:

E-mail: evangs.mailoa@uksw.edu pengunjung. Data pelayanan di perpustakaan merupakan hal yang penting untuk digunakan sebagai tolak ukur berkembangnya sebuak perpustakaan. Data pelayanan yang terdapat di Persipda terdiri dari beberapa kategori, antara lain Jumlah Pengunjung Perpustakaan, Jumlah Bahan Perpustakaan yang Dipinjam, Jumlah Peminjam, Jumlah Penambah Anggota, Jumlah Pengguna Koleksi Referensi, dll. Data tersebut penting agar pihak Persipda mengetahui jika terjadi penurunan atau peningkatan jumlah pelayanan. Perkembangan perpustakaan dapat diiukur dari besarnya 
gedung yang digunakan, jumlah koleksi yang tersedia, jumlah pengguna dan pngunjung, maupun teknologi informasi yang diterapkan (Widanarko, 2013). Saat ini data pelayanan di Persipda masih diolah dan dicatat secara manual menggunakan Microsoft Excel. Data tersebut dibagi menjadi empat bagian, yaitu data per bulan, data per trimester, data per semester, dan data per tahun. Petugas harus menginputkan masing-masing bagian kemudian mengolahnya hingga menghasilkan grafik pada tiap bagian dan tiap kategori. Kemudian apabila terjadi perubahan kategori, petugas harus mengubah beberapa bagian. Pencatatan yang masih manual dan belum terintegrasi menyebabkan data sering tidak valid.

Berdasarkan kasus tersebut muncul gagasan untuk membuat sebuah sistem informasi berbasis web yang berfungsi sebagai tempat pengolahan data pelayanan pengunjung di Persipda Salatiga. Adanya sistem informasi data pelayanan pengunjung yang berbasis web, data dapat diolah kapan saja dan tidak hanya mengandalkan satu device. Sistem informasi ini dibangun dengan menggunakan framework CodeIgniter yang memiliki arsitektur MVC (model view controller) untuk menjalankan fungsi-fungsinya, dengan CodeIgniter perancangan sistem dapat berjalan lebih cepat dan lebih terstruktur serta efisien dalam mengelola data yang banyak. Pembuatan user interface sistem informasi ini dibangun dengan menggunakan framework UIkit. Framework UIkit dapat menghasilkan sebuah web yang responsive atau dapat menyesuaikan di berbagai device. Keunggulan UIkit adalah ukurannya yang ringan dan dapat dimodifikasi dengan mudah (Uikit, 2013).

\section{KAJIAN PUSTAKA}

Pada penelitian dengan judul "Pembuatan Software Pencatatan Pengunjung Perpustakaan Menggunakan Barcode dan MySQL Berbasis Borland Delphi 7.0" dituliskan bahwa Pencatatan pengunjung perpustakaan penting karena merupakan salah satu point akreditasi mengenai jumlah pengunjung perpustakaan. Teknologi komputer dapat diterapkan dalam sistem pencatatan pengunjung perpustakaan untuk menggantikan kerja manual yang dilakukan manusia dengan lebih cepat dan efisien (Aprinana, 2009).

Pada penelitian berjudul

"Pengembangan dan Implementasi Pencatatan

Pengunjung Layanan Perpustakaan

Menggunakan Rapid Application

Development di Perpustakaan Universitas Universitas Kristen Satya Wacana" disebutkan bahwa CodeIgniter menerapkan kaidah MVC (Model View Controller). MVC digunakan untuk memisahkan komponen-komponen presentasi suatu aplikasi dengan komponen logika bisnisnya (Sikalak, 2011).

Berdasarkan penelitian terdahulu, maka dilakukan penelitian yang menghasilkan sebuah sistem informasi data pelayanan pengunjung Persipda Salatiga berbasis web yang dibangun dengan CodeIgniter dan Uikit. Sistem tersebut diharapkan dapat mempermudah proses pengolahan data pengunjung serta memberikan kemudahan akses informasi mengenai jumlah pengunjung di Persipda Salatiga melalui berbagai device.

Sistem informasi adalah suatu sistem disuatu organisasi yang mempertemukan kebutuhan pengolahan transaksi harian, mendukung operasi, bersifat menejerial dan kegiatan strategi dari suatu organisasi dan menyediakan pihak luar tertentu dengan laporan-laporan yang diperlukan (Jogiyanto, 1990). Data adalah bentuk yang masih mentah yang belum dapat bercerita banyak, sehingga perlu diolah lebih lanjut. Data diolah melalui model untuk dihasilkan informasi (Mhant One, 2015).

Pelayanan merupakan unsur utama dalam pencapaian suatu keberhasilan organisasi perpustakaan disebabkan bagian inilah yang berhubungan langsung dengan pengguna dalam penyebaran informasi serta pemanfaatan jasa dan fasilitas yang ada di perpustakaan. Pelayanan pepustakaan mencakup semua kegiatan pelayanan kepada pengguna yang berkaitan dengan pemanfaatan, penggunaan koleksi perpustakaan dengan tepat guna dan tepat waktu untuk kepentingan pengguna perpustakaan (Lansa, 1994).

CodeIgniter adalah aplikasi open source yang berupa framework dengan model MVC untuk membangun website dinamis dengan PHP. CodeIgniter tergolong framework dengan ukuran kecil dan cukup mudah untuk dikuasai. CodeIgniter juga 
datang dengan manual tergolong lengkap. Proses data mengalir pada sistem yang menggunakan CodeIgniter dapat diilustrasikan pada gambar berikut :

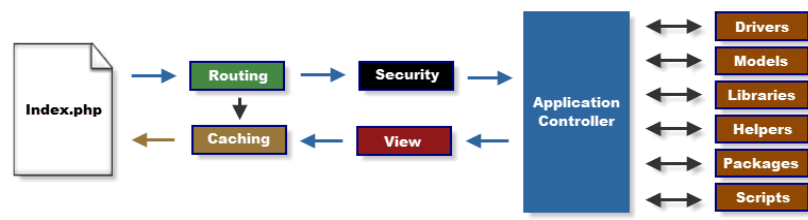

Gambar 1 Alur proses data pada CodeIgniter (Pressman, 2001)

UIKit merupakan sebuah framework yang berfungsi untuk membangun interface pada sebuah web. UIKit merupakan revolusi baru dari sebuah framework tang mulai dikembangkan pada Juli 2013 oleh YOOTheme yang merupakan salah satu penyedia tema yang populer. UIKit memiliki banyak koleksi komponen HTML, CSS, dan JS yang mudah digunakan serta dimodifikasi. UIKit menawarkan 30 bentuk komponen yang dapat dimodifikasi, antara lain : Layout, Navigations, dan Elements. UIKit juga dapat dipadukan dengan CSS Framework yang lain. Untuk menghindari bentrok antara framework yang lain, UIKit memiliki class dengan prefix "uk-" pada setiap komponennya.

Terdapat beberapa alasan mengapa UIKit digunakan untuk membuat sebuah web. Diantaranya adalah ukurannya yang tergolong ringan, dapat dibuktikan dengan diagram berikut :

\section{UIKit $1.0 \quad 44 \mathrm{~Kb}$}

\begin{tabular}{l} 
Bootstrap 3.0 RC $\quad 68 \mathrm{~Kb}$ \\
\hline Bootstrap 2.3 \\
\hline
\end{tabular}

\section{Foundation 4.3} $161 \mathrm{~Kb}$

\section{Gambar 2 Perbandingan UIKit dengan CSS} Framework lain (Eugenesivokon, 2015)

Berdasarkan Gambar 2, UIKit memili ukuran lebih ringan dibandingkan Bootstrap dan Foundation, atau dapat dikatakan UIKit adalah light-weight framework. Selain ukurannya rang ringan kelebihan UIKit antara lain : memiliki banyak pilihan Fonts, dapat dipadukan dengan Google Fonts serta bersifat responsive, yaitu dapat menyesuaikan bentuk di berbagai device.

\section{METODE PENELITIAN}

Pada perancangan sistem informasi data pelayanan pengunjung melalui tahapan penelitian yang terbagi dalam empat tahapan, yaitu: 1) Identifikasi masalah, 2) Perancangan sistem, 3) Implementasi sistem, dan 4) Pengujian sistem dan analisis hasil pengujian.

\begin{tabular}{|c|}
\hline Identifikasi Masalah \\
\hline Perancangan Sistem \\
\hline \multicolumn{1}{|c|}{} \\
\hline Implementasi Sistem \\
\hline Pengujian Sistem dan Analisis Hasil Pengujian \\
\hline
\end{tabular}

Gambar 3 Tahapan penelitian.

Tahapan penelitian pada Gambar 3 dapat dijelaskan sebagai berikut: 1) Tahap pertama: Identifikasi Masalah, pada tahap ini dilakukan identifikasi terhadap permasalahan yang ada, mendapatkan data dan literature yang terkait serta mengamati proses bisnis terkait proses pelayanan pengunjung di Persipda Salatiga. 2) Tahap kedua, Perancangan Sistem, tahap ini dilakukan perancangan sistem yang meliputi perancangan proses menggunakan diagram Unified Modelling Language (UML) dan perancangan database. Perancangan proses menggunakan UML meliputi use case diagram, activity diagram, dan class diagram. 3) Tahap ketiga: Implementasi Sistem, yaitu membuat sistem informasi berbasis web sesuai perancangan proses pada tahap kedua. 4) Tahap keempat: Pengujian sistem dan Analisis Hasil Pengujian, selanjutnya dari hasil implementasi akan dilakukan pengujian untuk melihat apakah sistem yang telah dibuat sudah sesuai dengan yang diharapkan atau tidak ada error, jika belum sesuai maka akan dilakukan perbaikan.

Pada tahap pengidentifikasi masalah, proses penelitian dilakukan identifikasi terhadap permasalahan yang ada dengan melakukan wawancara, mendapatkan data yang berkaitan dengan pelayanan pengunjung, 
framework Codeigniter dan UIkit. Wawancara dilakukan dengan cara tanya jawab dengan Supervisor di Persipda Salatiga. Berdasarkan hasil wawancara permasalahan yang ada didefinisikan sebagai berikut: 1) Dibutuhkannya sistem untuk mengelola data pelayanan pengunjung berbasis web. 2) Dibutuhkannya sistem yang dapat mempermudah akses terhadap layanan pengunjung di Persipda Salatiga. Selain itu dari hasil wawancara didapatkan proses bisnis terkait proses pendataan pelayanan pengunjung di Persipda Salatiga sebagai berikut :

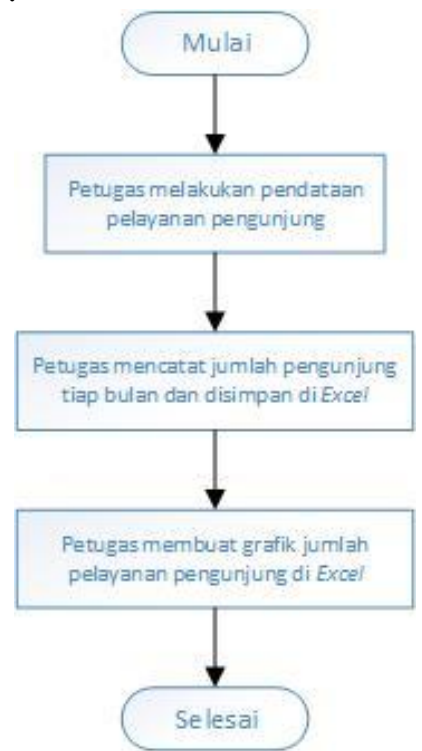

Gambar 4 Flowchart Proses Pendataan Pelayanan Pengunjung di Persipda Salatiga

Gambar 4 merupakan alur petugan untuk melakukan pendataan pelayanan pengunjung di Persipda Salatiga. Petugas melakukan pendataan pengunjung dan mencatat jumlah pengunjung tiap bulannya. Kemudian data disimpan di Excel. Setelah data didapatkan, petugas membuat grafik untuk mengetahui terjadinya peningkatan atau penurunan jumlah pengunjung yang memanfaatkan fasilitas di Persipda Salatiga sesuai data yang sudah dicatat.

Metode yang akan digunakan pada untuk perancangan Sistem Informasi Data Pelayanan Pengunjung di Persipda Salatiga berbasis web adalah Prototype Model dimana suatu prototype suatu bentuk perkiraan awal dari suatu sistem dibangun, diuji, lalu dikerjakan ulang sesuai kebutuhan hingga akhirnya tercapai suatu prototype yang dapat diterima. Prototype Model merupakan metode perancangan dengan melakukan pendekatan dari sisi kebutuhan pengguna sistem.

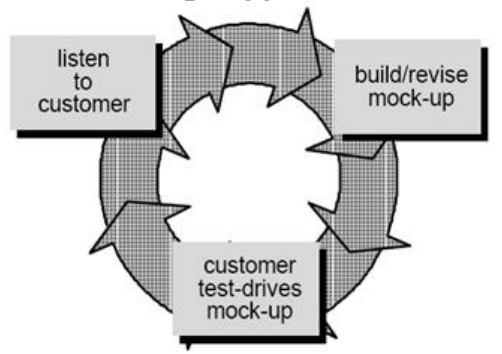

Gambar 5 Prototype Model (Pressman, 2001)

Tahap-tahap yang ada pada Gambar 5 adalah listen to customer dimana dilakukan wawancara dengan user untuk mengumpulkan kebutuhan-kebutuhan yang diperlukan dalam pembuatan sistem. Berdasarkan data dan kebutuhan sistem yang telah dikumpulkan lalu dilakukan tahap yang kedua yaitu build/revise mock-up. Pada tahap ini dilakukan proses perancangan sistem sesuai dengan kebutuhan pengguna. Perancangan sistem meliputi perancangan proses dan perancangan database. Perancangan proses dalam sistem menggunakan diagram Unified Modelling Language (UML). Kemudian dilakukan proses pembuatan prototype sesuai dengan hasil perancangan yang telah dibuat. Pada tahap selanjutnya hasil dari prototype kemudian dilakukan customer test-drives mock-up, yaitu sistem akan diberikan kepada pihak yang bersangkutan untuk dilakukan pengujian apakah sistem sudah sesuai dengan yang dibutuhkan. Hasil dari customer test-drive mock-up akan digunakan untuk pengembangan prototype selanjutnya. Tiga tahapan prototype dilakukan terus berulang sampai prototype yang dibangun sudah sesuai dengan kebutuhan pengguna. Tahapan pada metode prototype berakhir jika prototype yang dibangun sudah sesuai dengan kebutuhan pengguna dan siap untuk diimplementasikan.

Dalam pembangunan sistem, proses ini dilakukan 2 prototype yaitu: 1) Pada prototype 1 dilakukan perbaikan pada pengolahan data (insert, update, delete) yang dibagi tiap kategori. 2) Pada prototype 2 dilakukan penambahan grafik dalam jagka waktu triwulan, semester, dan satu tahun.

Perancangan proses menggunakan UML bertujuan untuk menggambarkan secara jelas alur yang ada pada sistem yang akan dibangun. Perancangan menggunakan UML meliputi use 
case diagram, activity diagram. Use case diagram menampilkan aktor, use case, dan hubungan antara use case. Perancangan use case diagram dibuat berdasarkan aktivitas yang dilakukan oleh admin dan user.

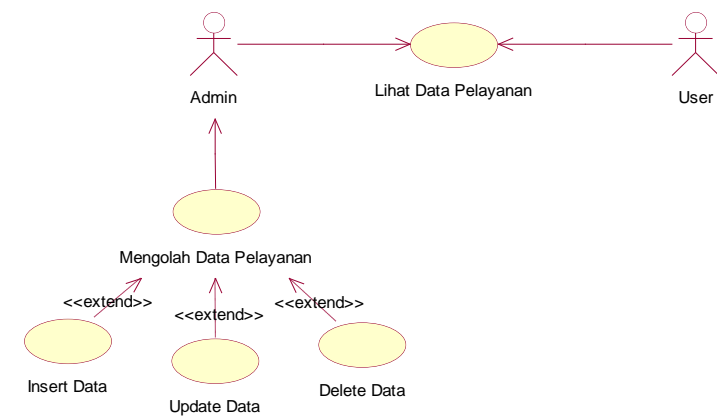

Gambar 6 Use Case Diagram Sistem

Gambar 6 menunjukkan use case diagram sistem informasi data pelayanan pengunjung Persipda Salatiga. Terdiri dari dua aktor, yaitu admin dan user. Admin bertugas untuk mengolah data pelayanan seperti menambah data, mengubah data, dan menghapus data. Admin juga dapat melihat data. User hanya dapat melihat data.

Activity diagram merupakan teknik untuk menggambarkan logika prosedur, proses bisnis, dan jalur kerja. Pada tahap ini perancangan activity diagram dibuat berdasarkan aktifitas yang dilakukan oleh admin dan user.

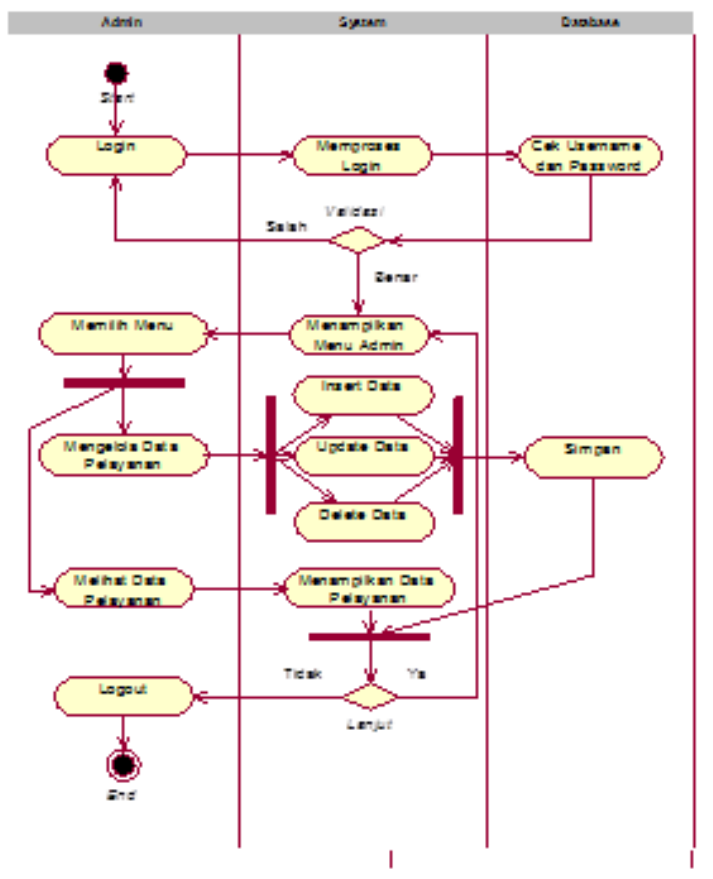

Gambar 7 Activity Diagram Admin

Gambar 7 menunjukkan activity diagram sistem informasi data pelayanan pengunjung Persipda Salatiga yang dilakukan oleh admin. Sebelum melakukan pengolahan data admin diharuskan untuk mengisi form login, apabila username dan password sesuai database maka admin dapat masuk ke halaman pengolahan data, jika username dan password tidak sesuai maka admin harus kembali ke halaman login. Pada halaman admin terdapat menu untuk pengolahan data. Data yang telah diolah admin kemudian akan disimpan ke database. Admin juga dapat melihat data pelayanan.

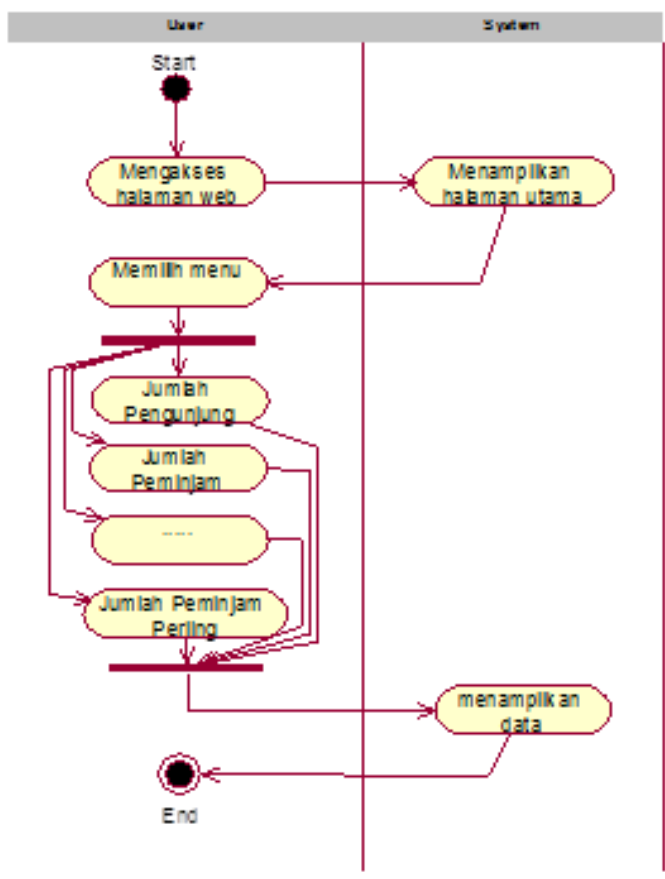

Gambar 8 Activity Diagram User

Gambar 8 menunjukkan activity diagram user. User melihat data dengan cara mengakses halaman web kemudian muncul halaman utama. User dapat memilih menu sesuai kebutuhan. Menu yang tersedia terdiri dari dua puluh satu kategori, antara lain data jumlah pengunjung, jumlah peminjam, dan jumlah peminjam perling. User dapat melihat data dalam bentuk tabel maupun grafik.

Class diagram merupakan diagram yang digunakan untuk menampilkan kelas yang ada dalam suatu sistem serta menggambarkan 
relasi antar kelas tersebut. Class diagram sistem yang terdapat pada rancangan sistem informasi arsip Salatiga, ditunjukkan pada Gambar 9.

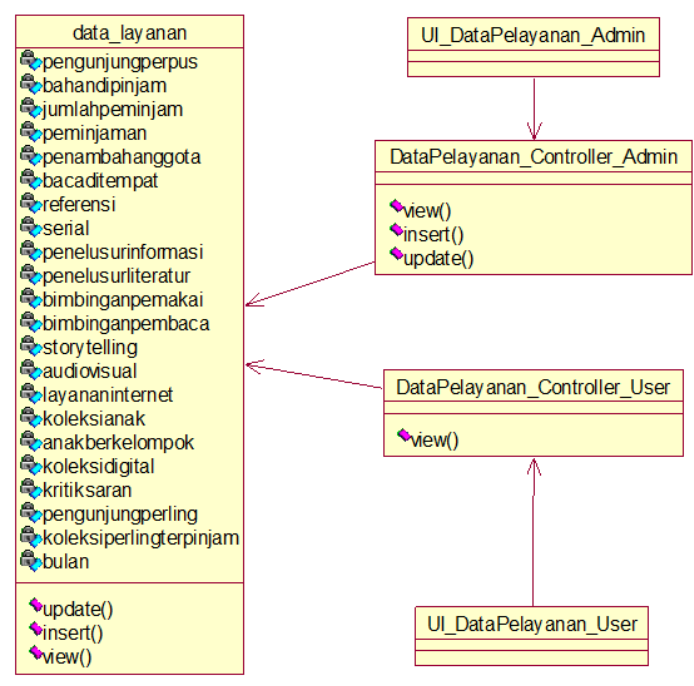

Gambar 9 Class Diagram Sistem

Terdapat relasi yang terjadi antara kelas view terhubung ke kelas controller. Sedangkan kelas controller dalam mengakses database harus melalui kelas model. Kelas Kategori memiliki beberapa realsi dengan kelas-kelas lainnya.

\section{HASIL DAN PEMBAHASAN}

Hasil implementasi sistem berdasarkan perancangan yang telah dibuat dijelaskan sebagai berikut. Sistem informasi ini memiliki dua sisi pengguna, yaitu admin dan user. Pada bagian admin diperlukan melakukan validasi login sebelum mengakses halaman admin untuk melakukan pengolahan data.

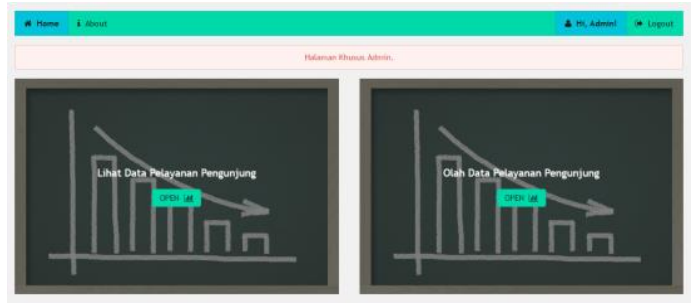

Gambar 10 Halaman Beranda Admin

Gambar 10 merupakan tampilan halaman beranda Admin. Admin dapat memilih menu lihat data pelayanan pengunjung dan olah data pelayanan pengunjung. Halaman pengolahan data ditunjukkan pada Gambar 11, admin dapat mengolah data sesuai kategori.

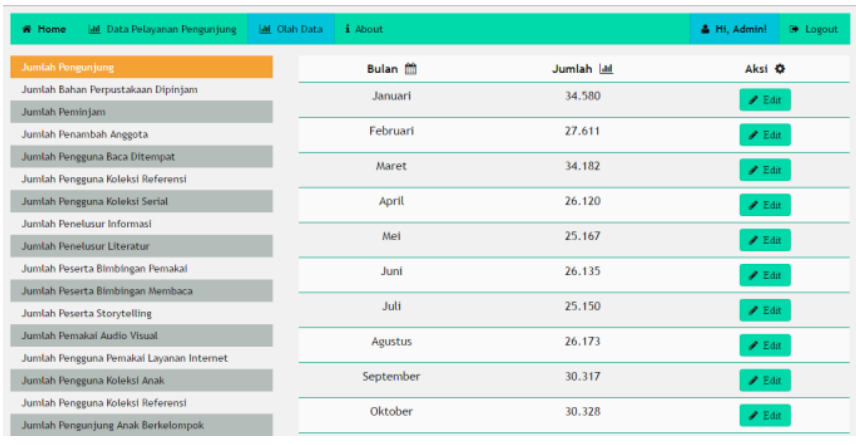

Gambar 11 Halaman Pengolahan Data Pelayanan Pengunjung

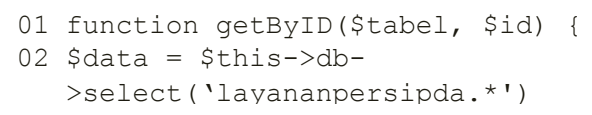

Pada halaman pengolahan data, admin dapat melakukan update atau edit jumlah pengunjung. Data tersebut ditampilkan dengan menggunakan fungsi untuk mendapatkan data dari database yang ditunjukkan pada Kode Program 1.

Kode Program 1 Perintah untuk mendapatkan data pelayanan pengunjung

Pada Kode Program 1 data diambil dari tabel layanan persipda dengan mendapatkan id. Fungsi tersebut kemudian diolah pada view agar terbentuk tabel.

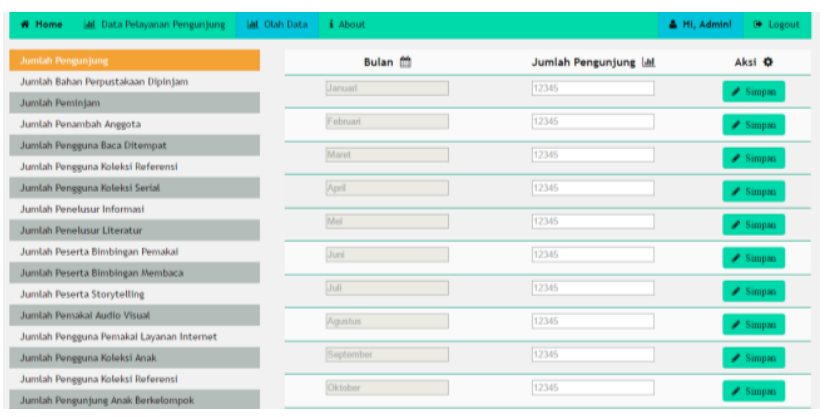

Gambar 12 Update Data Pelayanan Pengunjung.

Gambar 12 menunjukkan tampilan update data pelayanan pengunjung. Admin dapat mengubah jumlah pengunjung disesuaikan dengan bulan. Setelah selesai melakukan update, admin menekan button 
simpan agar data yang diubah trsimpan di database.

\section{Kode Program 2 Update Data Pelayanan}

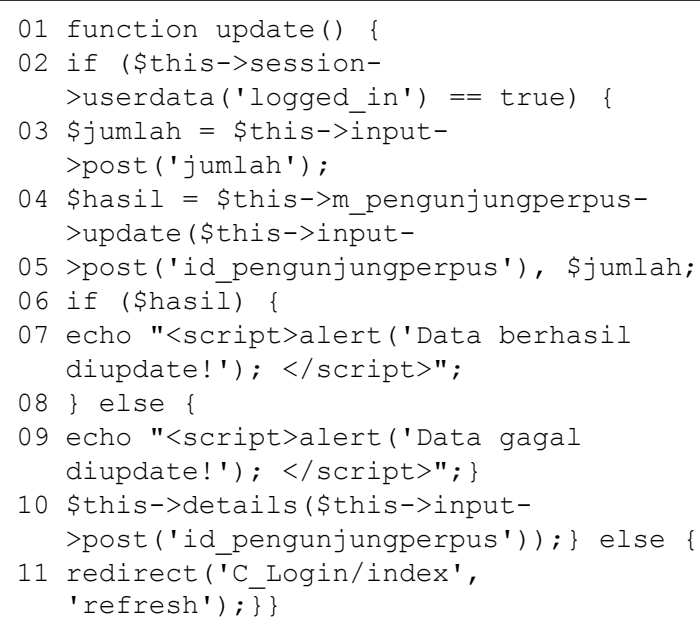

Pengunjung.

Pada Kode Program 2 terdapat fungsi update() pada controller m_pengunjungperpus, atribut-atribut data yang dikirim dari form dengan method post kemudian disimpan kedalam variabel yang kemudian dikirimkan sebagai parameter fungsi update() di model m_pengunjungperpus.

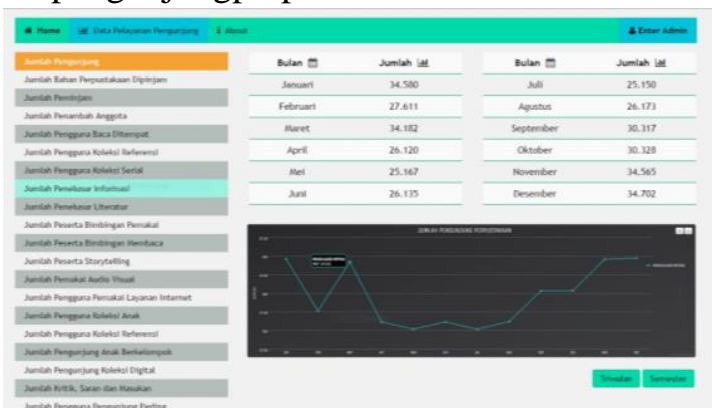

Gambar 13 Data Pelayanan Pengunjung

Gambar 13 menunjukkan tampilan data pelayanan pengunjung. Halaman tersebut dapat dilihat oleh user maupun admin. Terdapat beberapa kategori pelayanan pengunjung yang terdapat di sidebar. Pengguna dapat melihat data dari masingmasing kategori, seperti yang dicontohkan gambar diatas yaitu kategori Jumlah Pengunjung. Pada tiap kategori data ditampilkan dalam bentuk tabel dan grafik. Data pelayanan pengunjung juga disediakan dalam jangka waktu triwulan dan semester.

\section{Kode Program 3 Perintah untuk menampilkan Grafik}

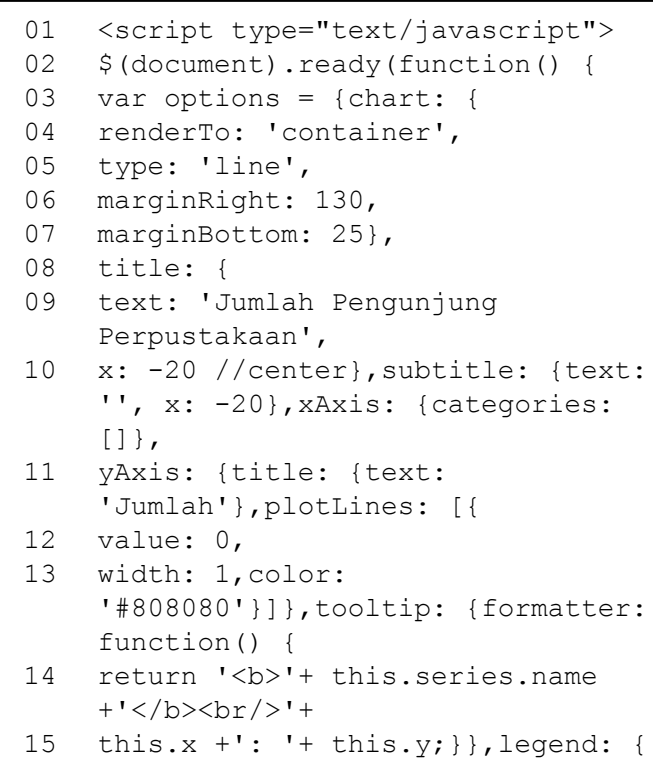

Kode Program 3 merupakan fungsi untuk menampilkan grafik yang terdapat pada view. Grafik dapat ditampilkan dengan menggunakan plug-in highcharts.js. Pade file view dilakukan pengaturan tampilan grafik, dengan mengubah xAxis, yAxis dan title sesuai yang dibutuhkan.

\section{Kode Program 4 Model Grafik}

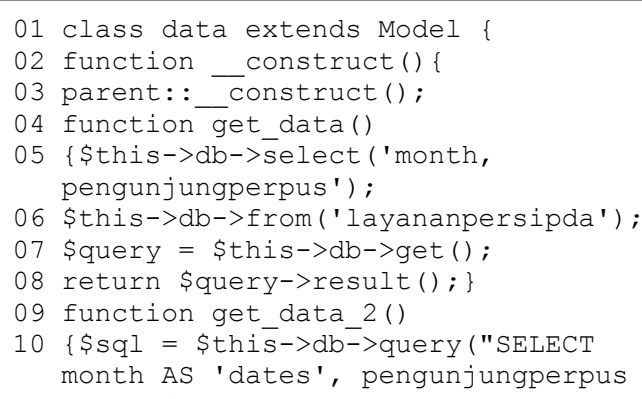

Kode Program 4 merupakan Model untuk menghubungkan highchart.js dengan database. Fungsi dari class model akan mengambil data dari database.

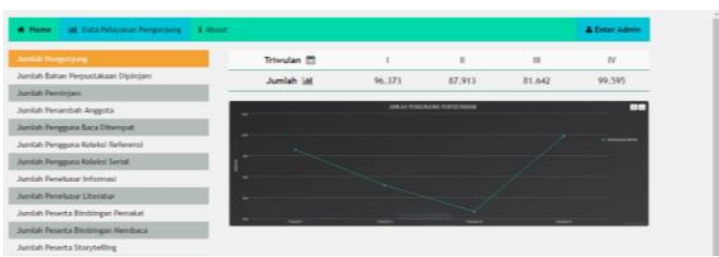

Gambar 14 Data Pelayanan Pengunjung dalam Jangka Triwulan 
Gambar 14 menunjukkan data pelayanan pengunjung dalam tiap triwulan. Data tersebut ditampilkan dalam tabel dan grafik. Data dalam jangka waktu triwulan menunjukkan peningkatan atau penurunan yang terjadi selama tiga bulan.

Pengujian sistem dilakukan untuk menguji semua fungsi yang telah dibuat pada sistem. Pengujian Sistem Informasi Pengunjung menggunakan teknik pengujian alpha. Pengujian alpha adalah pengujian sistem yang dilakukan pada semua orang yang terlibat dalam pembutan sistem. Pengujian alpha menggunakan metode blackbox yaitu pengujian fungsi-fungsi sistem secara langsung tanpa memperlihatkan alur eksekusi program. Tabel hasil pengujian dapat dilihat pada Tabel 1 .

Tabel 1 Hasil Pengujian Sistem Menggunakan Metode Blackbox

\begin{tabular}{|c|c|c|c|}
\hline $\begin{array}{c}\text { Fungsi } \\
\text { yang diuji }\end{array}$ & $\begin{array}{l}\text { Output yang } \\
\text { diharapkan }\end{array}$ & $\begin{array}{l}\text { Output dari } \\
\text { Sistem }\end{array}$ & $\begin{array}{c}\text { Status } \\
\text { Pengujian }\end{array}$ \\
\hline $\begin{array}{l}\text { Login } \\
\text { admin }\end{array}$ & Login berhasil & $\begin{array}{l}\text { Jika } \\
\text { username } \\
\text { dan } \\
\text { password } \\
\text { salah, maka } \\
\text { gagal login. } \\
\text { Jika benar, } \\
\text { maka sukses } \\
\text { login dan } \\
\text { dapat masuk } \\
\text { ke halaman } \\
\text { utama }\end{array}$ & Valid \\
\hline $\begin{array}{l}\text { Mengubah } \\
\text { data } \\
\text { pengunjung }\end{array}$ & $\begin{array}{l}\text { Data berhasil } \\
\text { diupdate ke database }\end{array}$ & $\begin{array}{l}\text { Data } \\
\text { pengunjung } \\
\text { berhasil } \\
\text { diubah ke } \\
\text { database }\end{array}$ & Valid \\
\hline $\begin{array}{l}\text { Melihat } \\
\text { statistik } \\
\text { data } \\
\text { pelayanan } \\
\text { pengunjung }\end{array}$ & $\begin{array}{l}\text { Chart data } \\
\text { pengunjung berhasil } \\
\text { ditampilkan }\end{array}$ & $\begin{array}{l}\text { Sistem } \\
\text { berhasil } \\
\text { menampilkan } \\
\text { chart data } \\
\text { pengunjung. } \\
\text { Chart } \\
\text { berubah } \\
\text { apabila } \\
\text { jumlah data } \\
\text { pengunjung } \\
\text { bertambah }\end{array}$ & Valid \\
\hline
\end{tabular}

Berdasarkan hasil pengujian sistem menggunakan teknik blackbox pada Tabel 1 dapat dilihat status semua fungsi adalah valid, maka disimpulkan bahwa fungsi-fungsi pada sistem yang diujikan berjalan dengan baik dan menghasilkan output yang sesuai harapan.

\section{SIMPULAN}

Berdasarkan uraian di atas, dapat disimpulkan bahwa sistem informasi data pelayanan pengunjung dibangun dengan menggunakan framework CodeIgniter dan UIkit. Sistem infomasi tersebut digunakan untuk mengetahui jumlah pengguna layanan pengunjung yang terdapat di Persipda Salatiga. Sistem informasi ini dilengkapi dengan fitur highchart untuk menampilkan statistik data pengunjung berdasarkan bulan, triwulan, dan semester. Statistik data pengunjung penting untuk diketahui apabila terjadi peningkatan atau penurunan jumlah pengguna layanan pengunjung di Persipda. Penelitian ini menghasilkan sistem informasi pengunjung berbasis web. Sistem informasi data pelayanan pengunjung dapat mempermudah petugas Persipda untuk melakukan pengolahan data yang pada proses sebelumnya masih menggunakan Microsoft Excel dan membuat grafik secara manual. Sistem informasi ini membantu meningkatkan kualitas layanan pengunjung di Persipda.

Sistem informasi data pelayanan bengunjung diharapkan dapat dikembangkan pada penelitian selanjutnya, seperti menambahkan menu untuk pengolahan kategori pelayanan.

\section{DAFTAR PUSTAKA}

Apriana, Hernowo Danusaputro. (2009). Pembuatan Software Pencatatan Pengunjung Perpustakaan Menggunakan Barcode dan MySQL Berbasis Borland Delphi 7.0. Semarang : Fisika - Universitas Diponegoro.

Eugenesivokon. (2015). Why Uikit is better than Twitter Bootstrap. http://www.eugenesivokon.com/blog/w 
hy-uikit-is-better-than-twitter-bootstrap (diakses pada 2 Juni 2016).

Jogiyanto. (1990). Analisis dan Desain Sistem Informasi Pendekatan Terstruktur. Penerbit ANDI: Yogyakarta.

Lansa. (1994). Pelayanan Perpustakaan. Jakarta.

Mhant One. (2015). Pengertian Sistem Informasi : Pengertian Data. https://nyeng29.wordpress.com/2015/02 /13/pengertian-sistem-informasi/ (diakses pada 1 Juli 2016).

Pressman, Roger, (2001). Software Engineering a Practitioner's Approach. New York : McGraw-Hill Higher Education.

Sikalak, Herwati. (2011). Pembangunan Aplikasi Rapor Berbasis Web Menggunakan CodeIgniter Framework (Studi Kasus : SMA Shandy Putra Dayeuhkolot). Bandung : Manajemen Informatika Politeknik Telkom.

UIkit. (2013). All UIkit core components at a glance. http://www.getuikit.com (diakses pada 10 Juni 2016)

Widanarko, Danang. (2013). Pengembangan dan Implementasi Pencatatan Pengunjung Layanan Perpustakaan Menggunakan Rapid Application Development di Perpustakaan Universitas - Universitas Kristen Satya Wacana. Salatiga : FTI-UKSW. 